\title{
A holistic framework for reshaping urban energy infrastructure in Global South cities, a case study of the Greater Cairo Region, Egypt
}

Yesmeen Khalifa ( $\nabla$ y.khalifa@keele.ac.uk)

Sharon George

Philip Catney

\section{Case Report}

Keywords: Urban energy infrastructure, Cairo Region, Egypt, Global South cities, Sustainable development

Posted Date: November 2nd, 2021

DOI: https://doi.org/10.21203/rs.3.rs-1007802/v1

License: (c) (i) This work is licensed under a Creative Commons Attribution 4.0 International License.

Read Full License 


\begin{tabular}{|c|c|}
\hline 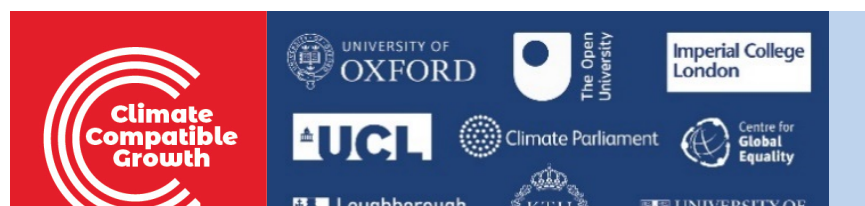 & 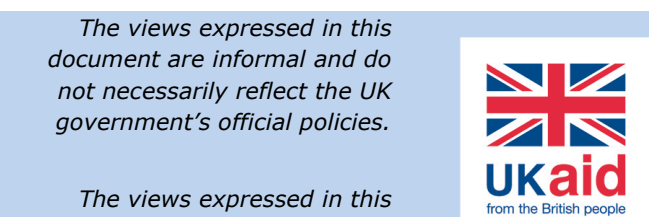 \\
\hline
\end{tabular}

\title{
A holistic framework for reshaping urban energy infrastructure in Global South cities, a case study of the Greater Cairo Region, Egypt
}

\author{
Yesmeen Khalifa, Sharon George, and Philip Catney
}

\section{Key Messages}

- Cities are complex systems that need integrated approaches to understand their characteristics and to identify challenges and opportunities for sustainable development.

- Context-based and tailored solutions are required for achieving SDGs and developing circular flows. This is particularly important in the Global South.

- Integrated and cross-sectoral planning and collaboration are necessary to improve the development of sustainable strategies and interventions to reduce trade-offs. Areas like the Greater Cairo Region in Egypt demonstrate the complexities of action across formal/informal sectors of waste management.

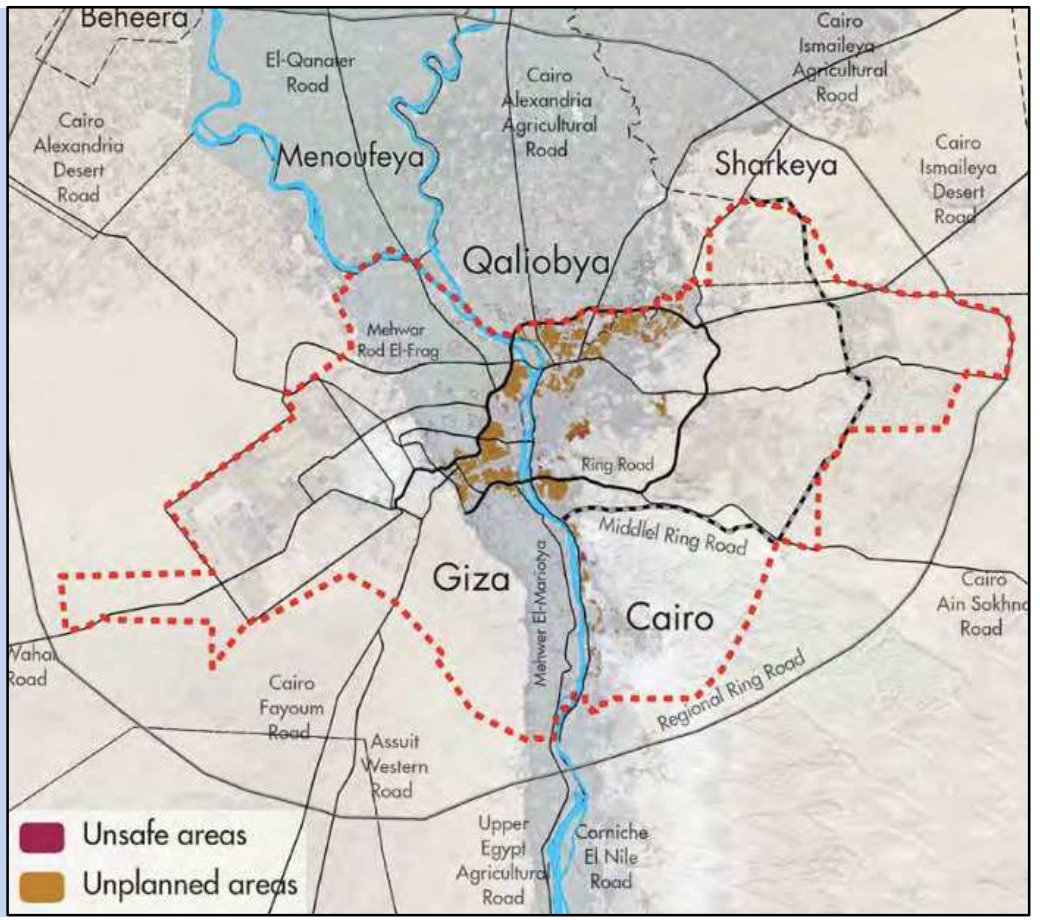

Figure 1: The unplanned areas in the main urban mass in Greater Cairo Region, Egypt [1].

\section{Introduction}

Resource scarcity and climate change are key challenges confronting urban sustainability in the Global South. Effective resource management is crucial for reducing the use of primary resources (e.g., fossil fuels) and maximizing renewable energy and secondary resource use (including solid waste and wastewater). There is growing interest in urban metabolism (UM) as a holistic framework to quantify and analyse the flow of resources, changes in consumption and production patterns over time, and to assess the effect of the system's social, economic, political, natural, and biophysical characteristics on the flow of resources [2-7]. The analysis of UM is an important step towards effective resource management [5-7] and achieving sustainable development goals. UM analysis assesses the level of circularity of resource streams to identify deficiencies in urban systems and opportunities for sustainable improvement $[2,4]$. The metabolism of cities changes over time [8] and climate change is expected to affect cities, regions, and countries in different ways [9]. Understanding the impacts of climate change on a city's metabolism is necessary to identify future challenges and develop suitable mitigation and adaptation strategies $[9,10]$.

This policy briefing is based on research undertaken in the Greater Cairo Region (GCR), Egypt [9], that examines the urgency and challenges of undertaking UM studies in the Global South. 


\section{Methodology}

The UM framework was applied to the constituent cities ${ }^{1}$ (Cairo, Giza, and Qalyubia) of the GCR, one of Africa's largest megacities, which is subject to rapid population growth and urbanization pressures (Figure 1). The study used a multi-layered indicator set [5] to collect data on population, economy, biophysical characteristics, consumption and production of energy, electricity and water, generation of solid waste and wastewater, and access to basic services [9]. Data were collected from 2000 to 2016 to identify changes in consumption and production patterns over time.

Semi-structured interviews with high-level key stakeholders ${ }^{2}$ were conducted in 2018 to understand the role of local authorities in providing basic services and to contextualize the data in terms of resource management challenges in various low, medium, and highdensity, planned and unplanned urban settlements. Site visits were undertaken to multiple types of settlement to observe these challenges.

This policy briefing focuses on the challenges and opportunities of reshaping the urban energy infrastructure (particularly electricity) in the constituent cities of GCR. The lessons from Egypt reveal various important challenges to cities in the Global South.

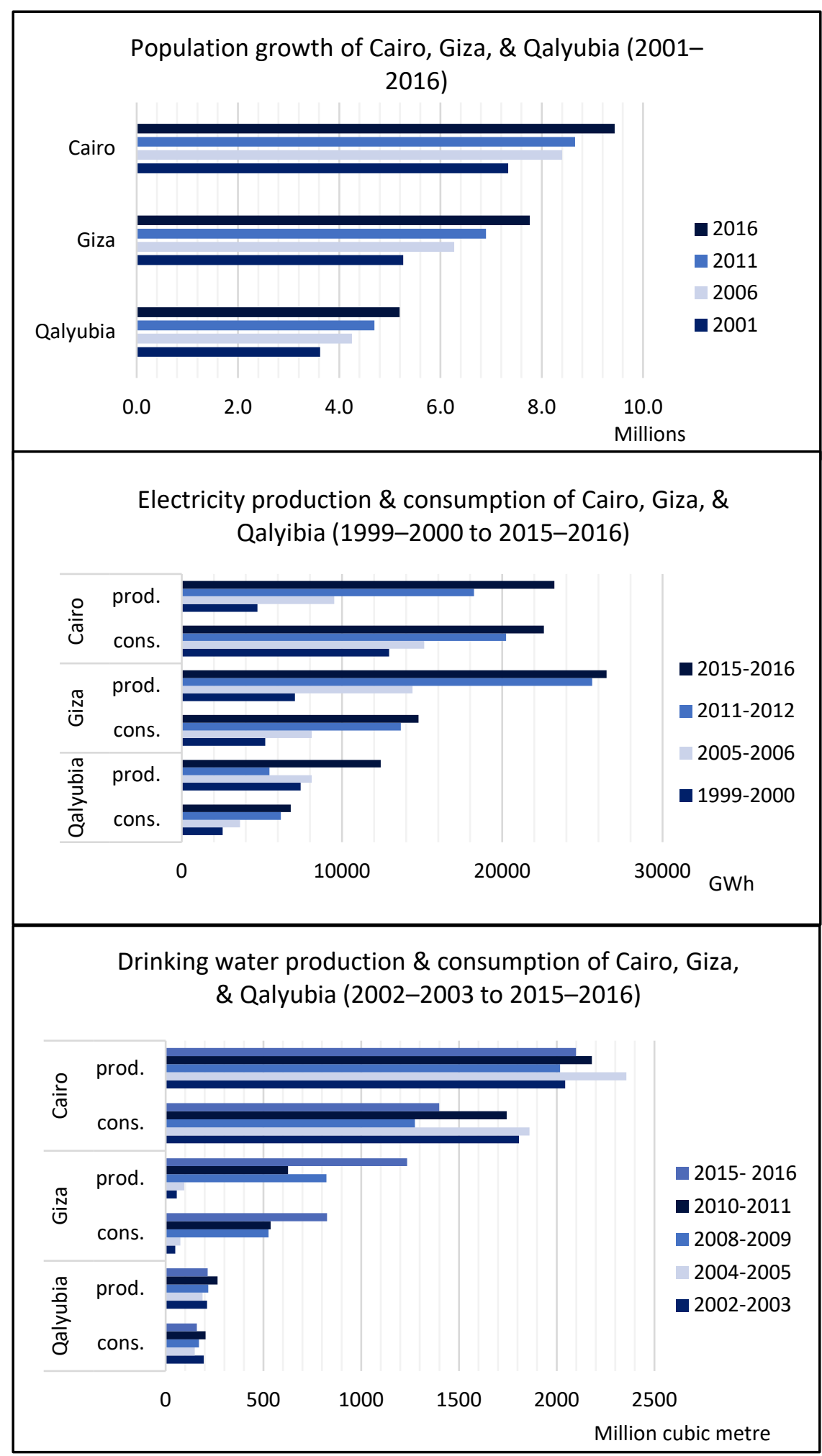

Figure 2: Population growth, electricity production and consumption, and drinking water production and consumption of Cairo, Giza, and Qalyubia [9].

\footnotetext{
1 The total area of Greater Cairo Region is almost 3.3 thousand square kilometres, of which $48 \%$ is in Cairo Governorate, $47 \%$ in Giza Governorate, and 5\% in Qalyubia Governorate [1,9].

2 High-level key stakeholders from the Ministry of Environment, the Ministry of Electricity and Renewable Energy, the Holding Company for Water and Wastewater, and the Cairo Cleaning and Beautification Authority [9].
} 


\section{Key findings}

- GCR cities rely mainly on primary resources such as nonrenewable energy resources (natural gas and oil), electricity, and fresh drinking water. The production and consumption of these resources changed between 2000 and 2016, based on population growth and urbanization, resource availability, infrastructure quality, and access to basic services (Figure 2) [9].

- Official statistics showed the average yearly electricity losses in Egypt as $14-16 \%$ between 2005 and 2016, though primary data collected showed this as $18 \%$ [9]. Higher losses are expected in GCR cities due to illegal connections in unplanned settlements and ageing infrastructure.

- Water shortage is a critical challenge in Egypt, necessitating the development of desalination and wastewater treatment plants, increasing energy and electricity demands. GCR cities rely mainly on surface water (Cairo 99.9\%, Giza 94\%, and Qalyubia 60\% in 2016) for drinking water production and the main source of renewable surface water in Egypt is the Nile [9]. The share of Egypt is 55.5 billion cubic metres per year, a share fixed since 1959 when the High Dam was constructed [11]. Consequentially, with population growth in GCR, water consumption per capita is decreasing [9].

- The average water loss in GCR cities is $30 \%$ and could reach $40 \%$ in unplanned settlements [9]. The production and distribution of drinking water require considerable energy. So, when water losses increase, this means that a percentage of the energy that is used in the production and distribution of the drinking water is also lost.
- Distributed Renewable energy schemes in $\mathrm{GCR}^{3}$ confront several barriers: 1) high levels of shading from buildings in urban areas reducing solar efficiency (Figure 3); 2) many roofs are occupied, particularly in high-density settlements, and the ownership patterns are not identified, creating problems in identifying how cost and risksharing should be apportioned; 3 ) existing grid infrastructure is unable to operate with different types of energy resources; and 4) the lack of adequate infrastructure and illegal connections in unplanned settlements.

- The long-term subsidization of energy and electricity has stalled the development of renewable energy projects [9]. The government developed a five-year tariff reform project (2014-2019), but this programme's completion has been delayed to 2022 [12].

- With an expected increase in solid waste and wastewater there is potential for the development of sludge-to-energy and waste-to-energy projects. Major challenges remain: the lack of reliable data; low coverage of solid waste col- lection and the lack of an integrated solid waste management system.

- The low percentage of waste collection coverage in GCR provides misleading data on actual solid waste generation and composition. Many partners are involved (formal and informal) in the solid waste sector so the government cannot properly coordinate the governance of this sector, and it is difficult to exchange data between partners.

- The capacity factor ${ }^{4}$ of solar and wind energy is higher than waste-to-energy and sludge-toenergy, but the sustainability benefits of the latter technologies ensure the effective handling of organic waste and sludge, reducing environmental and public health impacts.

- Data for 2017 indicate that most of households in GCR rely on natural gas for cooking (Cairo 70.2\%, Giza-urban areas $65.8 \%$, Qalyubia-urban areas $64.9 \%$ ) [9]. There is potential to upgrade organic waste that represents approximately 50$60 \%$ of the total municipal solid waste to produce biogas as a source of renewable energy [9].

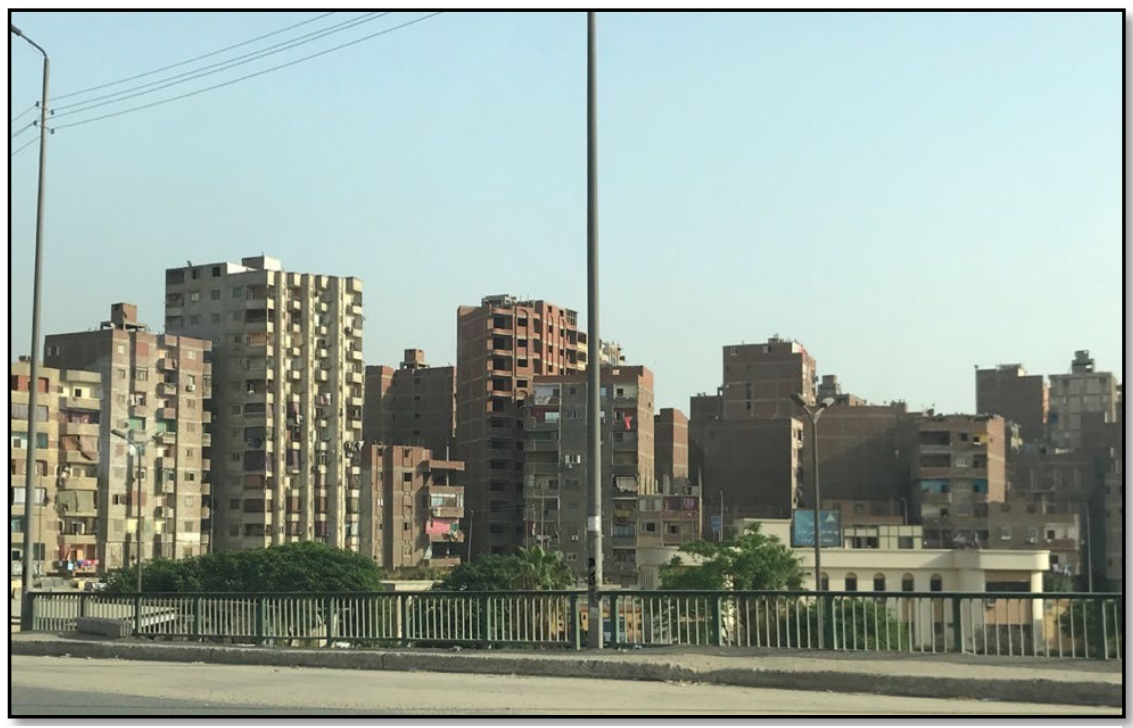

Figure 3 : high levels of shading from buildings, reducing solar efficiency in high-density settlements in GCR [9].

\footnotetext{
3 There is a huge potential for solar energy in Cairo, Giza, and Qalyubia as the average direct normal irradiation is 2,044, 2,057, and 1,949 $\mathrm{kWh} / \mathrm{m}^{2} /$ year, respectively [9].

${ }^{4}$ Capacity factor is defined as the actual electricity production divided by the maximum possible electricity output of a power plant, over a period of time [13] and it allows comparing different facilities or even technologies [14].
} 


\section{Recommendations}

The UM framework provided a better understanding of the local characteristics of the Greater Cairo Region and identified the key challenges and opportunities for sustainable resource management (or low-carbon development). To develop circular resource flows, the following measures are recommended:

\section{Energy and electricity}

- Develop and upgrade existing infrastructure to receive and transmit different types of energy, including the development of new technologies. This will enable the government to diversify the energy and electricity generation mix.

- Increase the quality of available data to identify production and consumption patterns. This could, for example be achieved through the increased installation of smart meters. But such measure should consider that resource consumption differs from one settlement to another.

- Use waste-to-energy and sludge-to-energy technologies in medium and high-density settlements and solar energy in low-density settlements and satellite cities.

\section{Solid waste and wastewater}

- Increase the technical, financial, and institutional capacities of solid waste and wastewater sectors to maximize the development of sludge-toenergy and waste-to-energy projects. This will reduce nonrenewable energy use, carbon

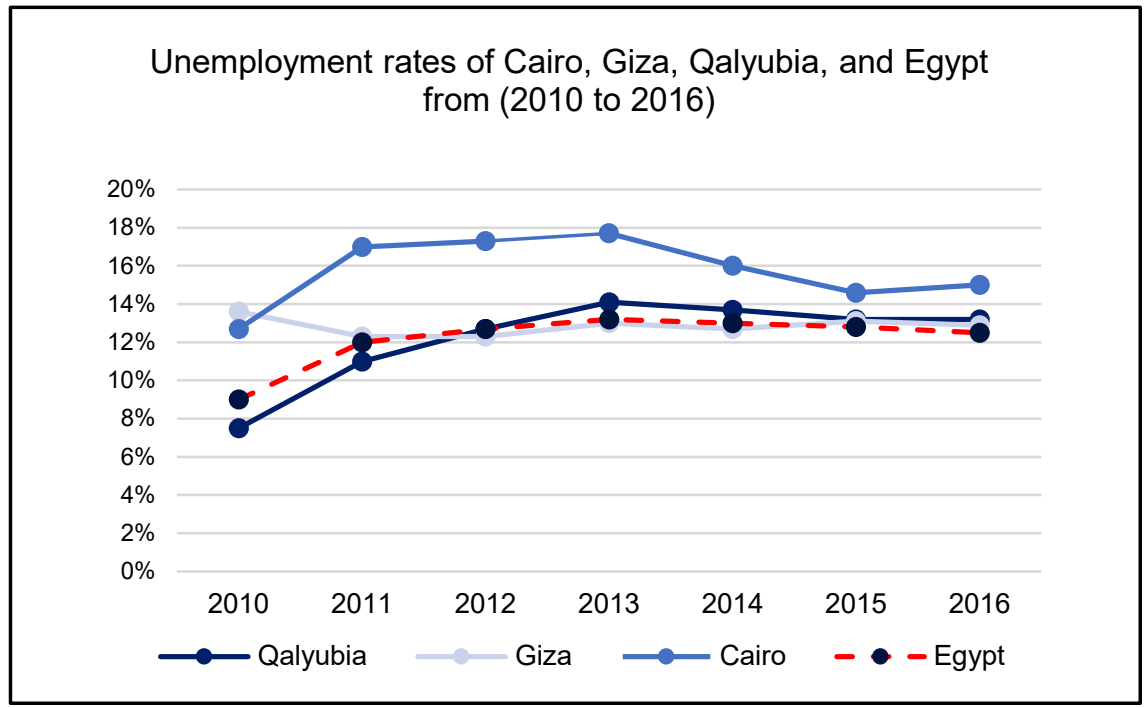

Figure 4: Unemployment rates of Cairo, Giza, Qalyubia, and Egypt [9].

dioxide emissions, and environmental impacts of solid waste and wastewater.

- Both sectors require a significant number of labourers, technicians, engineers, and a range of skills that could increase employment rates in GCR cities (Figure 4).

- Incorporate local knowledge of urban space use and waste management into planning processes to encourage more inclusive forms of urban sustainability.

\section{Social policy objectives}

- Create affordable settlements with access to basic services to meet expected population growth ${ }^{5}$ and to ensure adequate distribution of resources.

- Continued removal of nonrenewable energy and electricity subsidies to 1 ) increase the financial, institutional, and technical capacities of all sectors; and 2) encourage the use of alternative renewable energy resources. Any subsidy removal should be accompanied by schemes targeted at lowincome households to avoid exacerbating poverty.

- Increase public engagement and awareness campaigns to encourage behaviour change and sustainable energy and electricity consumption.

- Adopt holistic approaches to address sustainability challenges in the Global South. This requires understanding the flow of resources and changes in consumption-production patterns and identifying deficiencies in resource management systems. This will assist researchers and policymakers in creating context-based sustainability strategies and developing sustainable interventions.

5 The average annual population growth rates from 2001 to 2016 of Qalyubia is 2.77\%, Giza 3.17\%, and Cairo $1.91 \%$ [9]. 


\section{References}

[1] The General Organization for Physical Planning, (GOPP), (UNHabitat), the U.N.H.S.P. and the United Nations Development Programme, (UNDP) 2012. Greater Cairo Urban Development strategy, Part 1:

Future Vision and Strategic Directions. [Online]. Egypt: GOPP. Available from:

https://unhabitat.org/strategicdevelopment-of-greater-cairoenglish-version/.

[2] Ferrão, P. \& Fernández, J.E., 2013, Sustainable Urban Metabolism, The MIT Press, Cambridge, Massachusetts; London, England.

[3] John, B., Luederitz, C., Lang, D.J. \& Von Wehrden, H., 2019, Toward Sustainable Urban Metabolisms. From System Understanding to System Transformation, Ecological Economics, vol. 157, pp. 402414.

[4] Kalmykova, Y. \& Rosado, L., 2015, "Urban Metabolism as Framework for Circular Economy Design for Cities", World

Resources Forum (2015), Davos, 11 - 14 October 2015.

[5] Kennedy, C., Stewart, I.D., Ibrahim, N., Facchini, A. \& Mele, R., 2014, Developing a multi- layered indicator set for urban metabolism studies in megacities, Ecological Indicators, vol. 47, pp. 7-15.

[6] Kennedy, C. \& Hoornweg, D., 2012, Mainstreaming Urban Metabolism, Journal of Industrial Ecology, vol. 16, no. 6, pp. 780782.

[7] Pincetl, S. \& Bunje, P.M.E. 2009, Potential targets and benefits for sustainable communities research, development, and demonstration funded by the pier program: Prepared for California Energy Commission, UCLA Institute of the Environment, Los Angeles, CA.

[8] Kennedy, C., Cuddihy, J. \& Engel-Yan, J., 2007, The Changing Metabolism of Cities, Journal of Industrial Ecology, vol. 11, no. 2, pp. 4359.

[9] Khalifa, Y.A. 2021, Urban Metabolism: An integrated approach to exploring the challenges of resource management for urban sustainability in developing countries, PhD thesis, Keele University, UK.

[10] Céspedes Restrepo, J.D. \& Morales-Pinzón, T., 2018, Urban metabolism and sustainability:
Precedents, genesis and research perspectives, Resources, Conservation and Recycling, vol. 131, pp. 216-224.

[11] Wahba, S.M., Scott, K. \& Steinberger, J.K., 2018, Analyzing Egypt's water footprint based on trade balance and expenditure inequality, Journal of Cleaner Production, vol. 198, pp. 1526-1535.

[12] Khanna, A. and Rana, A. 2020. Learning from Power Sector Reform: The Case of the Arab Republic of Egypt. Policy Research Working Papers.

[Online]. Washington, DC, USA: The World Bank. Available from: http://elibrary.worldbank.org/doi /book/10.1596/1813-9450-9162.

[13] Neill, S.P. \& Hashemi, M.R. 2018, "Chapter 1 - Introduction" in Fundamentals of Ocean Renewable Energy, eds. S.P. Neill \& M.R. Hashemi, Academic Press, pp. 1-30.

[14] Ibarra-Berastegi, G., Sáenz, J., Ulazia, A., Serras, P., Esnaola, G. \& Garcia-Soto, C., 2018, Electricity production, capacity factor, and plant efficiency index at the Mutriku wave farm (20142016), Ocean Engineering, vol. 147, pp. 20-29.

\section{Notes}

Climate Compatible Growth (CCG) programme: CCG is funded by the UK's Foreign Development and Commonwealth Office (FCDO) to support investment in sustainable energy and transport systems to meet development priorities in the Global South.

\section{Authors}

- Dr Yesmeen Khalifa, Keele University, UK. Email: y.khalifa@keele.ac.uk - Dr Sharon George, Keele University, UK. Email: s.m.george@keele.ac.uk

- Dr Philip Catney, Keele University, UK. Email: p.j.j.catney@keele.ac.uk 